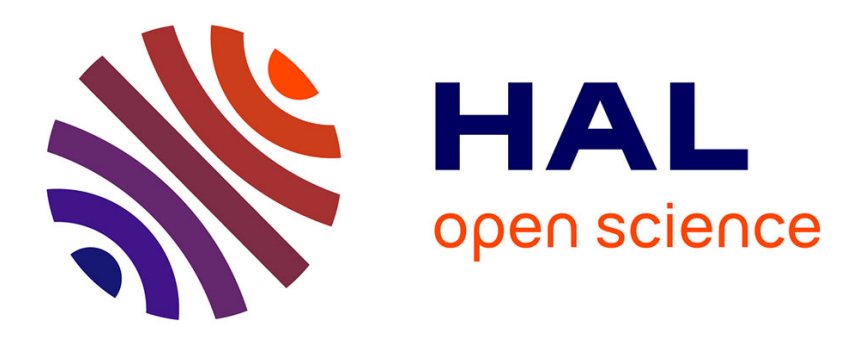

\title{
Digital Options and Efficiency in Experimental Asset Markets
}

\author{
Stefan Palan
}

\section{To cite this version:}

Stefan Palan. Digital Options and Efficiency in Experimental Asset Markets. Journal of Economic Behavior and Organization, 2010, 75 (3), pp.506. 10.1016/j.jebo.2010.05.011 . hal-00849410

\section{HAL Id: hal-00849410 https://hal.science/hal-00849410}

Submitted on 31 Jul 2013

HAL is a multi-disciplinary open access archive for the deposit and dissemination of scientific research documents, whether they are published or not. The documents may come from teaching and research institutions in France or abroad, or from public or private research centers.
L'archive ouverte pluridisciplinaire HAL, est destinée au dépôt et à la diffusion de documents scientifiques de niveau recherche, publiés ou non, émanant des établissements d'enseignement et de recherche français ou étrangers, des laboratoires publics ou privés. 


\section{Accepted Manuscript}

Title: Digital Options and Efficiency in Experimental Asset Markets

Author: Stefan Palan

PII: $\quad$ S0167-2681(10)00093-4

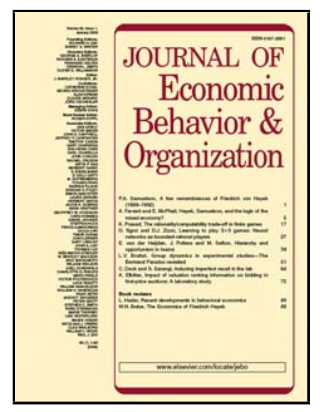

DOI: doi:10.1016/j.jebo.2010.05.011

Reference: $\quad$ JEBO 2546

To appear in: Journal of Economic Behavior \& Organization

Received date: $\quad 20-2-2009$

Revised date: $\quad 31-3-2010$

Accepted date: $\quad 11-5-2010$

Please cite this article as: Palan, S., Digital Options and Efficiency in Experimental Asset Markets, Journal of Economic Behavior and Organization (2008), doi:10.1016/j.jebo.2010.05.011

This is a PDF file of an unedited manuscript that has been accepted for publication. As a service to our customers we are providing this early version of the manuscript. The manuscript will undergo copyediting, typesetting, and review of the resulting proof before it is published in its final form. Please note that during the production process errors may be discovered which could affect the content, and all legal disclaimers that apply to the journal pertain. 


\title{
Digital Options and Efficiency in Experimental Asset Markets
}

\author{
Stefan Palan ${ }^{\mathrm{a}}$ \\ a Institute of Banking \& Finance, Karl-Franzens-University, Universitaetsstrasse 15/F2, 8010 Graz, Austria \\ stefan.palan@uni-graz.at, T: +43/316/380-7306, F: +43/316/380-9580
}

\begin{abstract}
In asset markets, extraordinary price run-ups (bubbles) followed by crashes back to levels closer to fundamental values have been shown to adversely affect the real economy, leading to inefficient resource allocation and underinvestment. Conversely, derivative markets contribute to price discovery and lead to informationally more efficient prices in the market for the underlying asset. We combine these observations and test experimentally whether digital options - a type of derivative that has recently been introduced to a wider audience via online prediction markets - can reduce price bubbles in a laboratory setting. We find that subjects do not use the derivative market to improve their expectations of future asset prices and analyze this result.
\end{abstract}

Keywords: Asset market, digital option, experimental economics, bubble, efficiency JEL classification: G01, D01, D02 


\title{
Digital Options and Efficiency in Experimental Asset Markets
}

\begin{abstract}
In asset markets, extraordinary price run-ups (bubbles) followed by crashes back to levels closer to fundamental values have been shown to adversely affect the real economy, leading to inefficient resource allocation and underinvestment. Conversely, derivative markets contribute to price discovery and lead to informationally more efficient prices in the market for the underlying asset. We combine these observations and test experimentally whether digital options - a type of derivative that has recently been introduced to a wider audience via online prediction markets - can reduce price bubbles in a laboratory setting. We find that subjects do not use the derivative market to improve their expectations of future asset prices and analyze this result.
\end{abstract}

Keywords: Asset market, digital option, experimental economics, bubble, efficiency

JEL classification: G01, D01, D02

THE RESEARCH QUESTION UNDERLYING THIS ARTICLE is motivated by three loosely related topics in financial economics. The first of them is the propensity of market prices to sometimes exhibit extraordinary run-ups (bubbles) followed by crashes back to levels closer to fundamental values. This phenomenon has been documented as early as after the disintegration of the tulip price bubble in the Netherlands in 1637 or the plunge in stock prices of the South Sea Company in the UK in 1720. In the last century, the Great Depression in the 1930s clearly demonstrated the danger that spillover effects from price bubbles in financial markets pose for the underlying real economy. The global financial crisis following the crash of a price bubble in U.S. real estate prices in 2007 forms another example that is and will continue to be subject to intense analysis in the coming years.

Bubble-and-crash patterns in financial market prices are widely considered harmful to economic activity in general, since they cause a misallocation of available resources to non-optimal uses. As a case in point, Gan (2007) documents how the adverse liquidity shock experienced by Japanese banks in the early 1990s led to reduced lending, which in turn had significant repercussions on both the real investments and the performance of capital-deprived Japanese firms. His study showcases an indirect transmission channel from asset market bubbles to the real economy, underlining the possible efficiency gains to be had from a better understanding of the bubble phenomenon.

The second strand of research impacting on our work saw its beginnings in the 1970s. Cox (1976) was one of the earliest articles to model the link between futures trading and the information processing taking place in the formation of spot market prices. Since then, an extensive branch of literature has been devoted to the connection between the trading of forwards, futures and options, and its impact on the informational efficiency of the market price of the underlying asset. Both theoretical 
and empirical studies have shown that derivatives markets generally process information earlier and faster than spot markets and that the creation of a derivatives market to accompany a spot market usually leads to higher price efficiency in the latter. ${ }^{1}$ One explanation for this effect is proposed by Figlewski and Webb (1993), who reason that options give traders who cannot or will not engage in short sales due to e.g. transaction costs, an opportunity to sell short indirectly.

The final component motivating our research is the emergence of a new type of online marketplace permitting the trading in digital options. Prediction markets and online betting sites like betonmarkets.com, binarybet.com, intrade.com, ladbrokes.com, and mybet.com (among others) are relatively new ventures which allow investors to trade cash-or-nothing (digital) options on financial market prices. A cash-or-nothing option returns a fixed cash amount in the case that it expires in the money and nothing if it expires out of the money. These options are sometimes referred to as 'binary bets' in real-world markets and are being marketed as being easier to understand than conventional bets (cp. Oliver 2007). The sites mentioned above have in common that there are low barriers to entry and that trades can be initiated with relatively small investment volumes and transaction costs.

Our article brings together the above three pieces of motivation. It aims at providing evidence regarding the question of whether the adverse effects of price bubbles in financial markets can be reduced if markets are provided with the forward-looking price information from digital option markets. We attempt to uncover the effects of giving traders an opportunity to trade digital options under the controlled conditions of a laboratory experiment. The design we employ is a modification of the experimental double auction asset market introduced in Smith et al. (1988).

The rest of this article is structured as follows: Section 1 discusses some background issues and develops our hypotheses. Section 2 then introduces our experimental design. Section 3 reports the results of our experiments and provides a brief comparison with previous results from the literature. Section 4 concludes the paper and proposes possible future research questions. An Appendix is provided in section 5.

\section{Background and Hypothesis}

Our experiment is modeled after the seminal contribution of Smith et al. (1988). They find that although the possible dividend draws in their laboratory markets are common information and every trader has all the information required to derive the fundamental value of the stock in every period, there is a persistent pattern across inexperienced subjects: The stock price starts out below its fundamental value in period 1. Over the course of the experiment, the stock price then rises above its

\footnotetext{
${ }^{1}$ O'Hara (1995) is one of the best sources for theoretical work on this topic. In an empirical study, Easley et al. (1998) show that option volumes lead stock price changes and carry information about future stock price changes. Similarly, Jayaraman et al. (2001) find that option markets lead equity markets in terms of volume. Chakravarty et al. (2004) employ an approach pioneered by Hasbrouck (1995) to measure that between a stock and an option market, on average between 17 and 18 percent of price discovery occurs in the option market.
} 
fundamental value, creating a bubble. During the final periods, the price crashes down to levels close to its fundamental (intrinsic dividend) value.

These results have in the past 20 years been replicated numerous times, with a wide array of variations, and have been found to be remarkably robust. ${ }^{2}$ The only variable that has been widely observed to reliably lead to a disappearance of the observed bubbles is experience. Subjects who have played the same experiment once or twice before produce a price series that follows the fundamental price series significantly more closely, with bubbles usually vanishing entirely by the second repetition. While not leading to a disappearance of bubbles, the addition of a derivatives market to the spot asset market has been found to cause a decline in measures of the extent of price bubbles. Forsythe et al. $(1982,1984)$ use a somewhat different design than that of Smith et al. (1988), but find that futures markets do accelerate convergence and that in the absence of futures markets, even experienced traders have problems overcoming the existing coordination problems. Friedman et al. (1983, 1984) conduct similar experiments and confirm the higher informational efficiency of asset market prices in the presence of a futures market. Porter and Smith (1995) introduce a futures market to the Smith et al. (1988) design, while staying true to the original institution in all other respects. They report a reduction of the amplitude of the observed price bubble in their spot-and-futures treatment relative to the spotonly treatment. In a different approach, De Jong, Koedijk and Schnitzlein (2006) modify the Smith et al. (1988) baseline experiments both by adding an option market to the spot market, and by introducing three market makers and an insider. They find that price efficiency in the asset market is higher and the asset's price volatility lower when the intrinsic value of the option is positive. They also note more generally that the presence of any option (i.e. even if its intrinsic value is zero) improves market efficiency.

The hypothesis we wished to explore with our experiment was that the constant visibility of the expected stock price in a future period (as revealed in a digital option market) leads to a reduction in the extent of the observed bubble. Our first design therefore closely resembles the Porter and Smith (1995) futures market discussed above. One reason why a market in derivative instruments might have an effect on the bubble phenomenon is that futures and option prices may convey in-

\footnotetext{
${ }^{2}$ Modifications of the original Smith et al. (1988) design were made with regard to many dimensions: Variations in dividends featured certain dividends (Porter and Smith 1995), a symmetric discrete dividend distribution with unequal probabilities over outcomes (Van Boening et al. 1993), variations in the structure of dividend payments over time (Smith et al. 2000, Caginalp et al. 2001, Oechssler et al. 2007), a dividend payment date beyond subjects' investment horizon (Hirota and Sunder 2007), a dividend regime that induced a non-monotonic fundamental value process (Noussair and Powell 2008), and an expected dividend of zero, yielding a constant expected asset value (Caginalp et al. 2001, Noussair et al. 2001). Some studies varied the reward function by employing play money instead of real money payouts (Smith 1962, Forsythe et al. 1982), introducing trading commissions and transaction costs (Friedman et al. 1983 and 1984, King et al. 1993), or deviating from the practice of payouts being linearly related to the wealth amassed in the experiment (James and Isaac 2000, Luckner and Weinhardt 2007). Another class of variations targeted the ability of subjects to short-sell (King et al. 1993, Sunder 1995, Ackert et al. 2006, Haruvy and Noussair 2006). An important variation was preventing speculation by assigning subjects the role of either buyer or seller (Lei et al. 2001). Other modifications concerned the transaction mechanism (Van Boening et al. 1993), multiple assets (Fisher and Kelly 2000), uninformative announcements (Corgnet et al. 2007), non-stationary repetition (Hussam et al. 2008), and computer simulation (Gode and Sunder 1993).
} 
formation about subjects' expectations. Since these revealed expectations form the basis of the actions market participants take, they have a direct impact on market prices. Apart from their effect by way of subjects' expectations, markets in derivative securities also serve to make the market more complete overall, by increasing the rank of the matrix of state-dependent security payoffs in the sense of Ross (1976). Note that outside the laboratory, derivative markets make up a substantial portion of financial markets overall. While the stock market had a total market capitalization of $\$ 36.98^{3}$ trillion and the debt market of $\$ 25.90^{4}$ trillion in June 2009, the notional amount of outstanding over-the-counter derivatives was $\$ 604.62^{5}$ trillion. Even though a large part of these derivatives cancel each other out when seen from a global perspective, these numbers nonetheless document the relevance of derivatives trading in the world economy.

Building on these results and observations, we conjecture that the opportunity of trading in a digital option market reduces the frequency and extent of bubble observations in markets of the type introduced in Smith et al. (1988), as quantified by the three standard bubble measures of amplitude, duration and turnover.

\section{Experimental Design}

\subsection{Stock and Option Markets}

Subjects in the experiment can trade over 15 periods in a market for an asset (referred to as a stock) and in a second market for digital options written on the asset. In keeping with the original Smith et al. (1988) design, the stock market employs the continuous double auction mechanism with a closed order book; also in line with Smith et al. (1988), bids and asks are constrained to be improving. At the end of each period, each share pays a random dividend after the market close. Dividends are drawn from a discrete uniform distribution with four equiprobable dividend values $(0,8,28$ or 60 euro cent). The stock has no terminal value, causing its fundamental value to decline by the expected dividend ( 24 cent) in each period.

In the digital option market, subjects can specify a price they expect the future stock price to exceed or fall short of (long or short position) and also specify the amount of their wealth they want to invest in this option. This quote is then entered into an (open) order book until it can be matched with a conflicting order by another subject. If for example a subject's order "bets" on prices greater than 100 (a digital call option with a strike price of 100), any other subject's order for a digital put option with a strike price smaller than or equal to 100 would lead to the creation of an option contract between these two subjects, with a strike price equal to the first subject's strike price of 100 .

We have two treatments, which differ with regard to the option maturity. In the digital options treatment DO8, options can be traded from periods 1 to 8; all options

\footnotetext{
${ }^{3}$ Bloomberg, symbol WCAUWRLD:IND, data for 2009-06-30.

${ }^{4}$ Bank for International Settlements (2009), p. A 85, data for June 2009.

${ }^{5}$ Bank for International Settlements (2010), p. A 121, data for June 2009.
} 
expire at the end of period 8 and are judged using the stock price at the end of period 8. Starting from period 9, the option market is closed. In DO5/10/15, options that are created in periods 1 to 5 expire at the end of period five, options created in periods 6 to 10 expire at the end of period 10 and options created in periods 11 to 15 expire at the end of period 15. This time structure is illustrated in Figure 1.

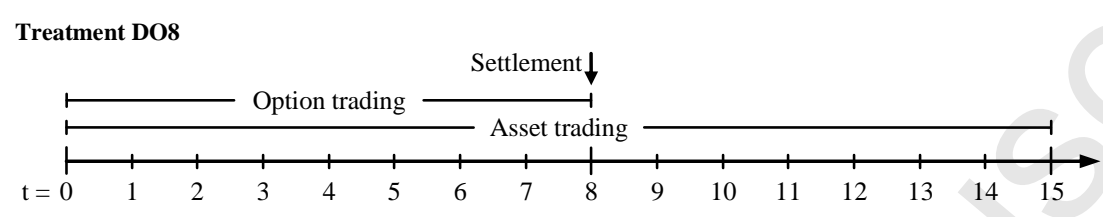

Treatment DO5/10/15

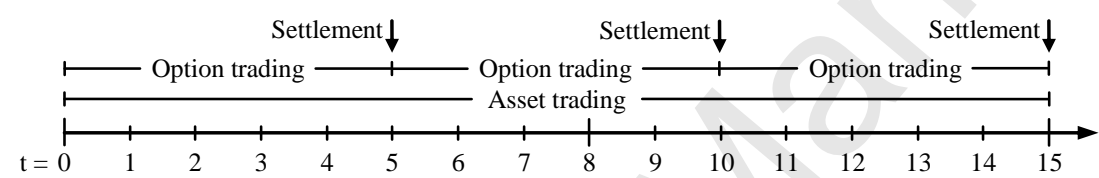

Figure 1. Time structure of spot and option trading, DO8 and DO5/10/15 treatments. Illustration of the time structure of spot and option trading in the DO8 (upper panel) and DO5/10/15 treatments. The stock trading structure is identical between treatments; option trading differs with regard to option maturity and because no option can be traded in periods 9-15 of treatment DO8.

Note that standard call (put) option contracts promise to pay nothing if they are out of the money at maturity, and an amount that increases linearly with increases (decreases) in the price of the underlying if they mature in the money. Since this implies that the payoff from such an option at maturity can be any non-negative number (subject to tick-size constraints), this payoff pattern is not easily understood by individuals inexperienced in financial matters. This problem is significantly abated when employing digital option contracts, which feature only three possible payoffs. Specifically, for our experiment, a subject's payoff from a digital option at maturity is:

$$
P O_{t=M, \theta}=\left\{\begin{array}{cc}
2 \cdot S I \cdot(1-\theta) & \text { iff } S_{M}<X \\
S I & \text { iff } S_{M}=X \\
2 \cdot S I \cdot \theta & \text { iff } S_{M}>X
\end{array}\right.
$$

where $M \in \mathbb{M}^{\mathrm{D} 08}=\{8\}$ is the option's maturity date in the DO8 treatment and $M \in \mathbb{M}^{\mathrm{D} 05 / 10 / 15}=\{5,10,15\}$ in the DO5/10/15 treatment, $\theta$ equals 1 if the subject holds a call and 0 if the subject holds a put option, $S I$ is the stake invested into the option by the subject, $S_{M}$ is the stock price at maturity and $X$ is the option's strike 
price. The profit from such an option then is $P O_{t=M, \theta}-S I{ }^{6}$. This payoff pattern is illustrated in Figure 2 below. All prices in the experiment are quoted in euro cent $(€ 0.01)$. There are no transaction costs in our stock and option markets.

Note that, due to the symmetric nature of the digital option contract, a long digital call option yields the same profit and loss pattern as a short digital put option, and vice versa. In a diagram such as the one in Figure 2, put options can generally (i.e. not only in the case of digital options) be derived from call options - and vice versa - by mirroring the payoff pattern around a line that is perpendicular to the $\mathrm{x}$-axis and intersects it at the option's exercise price. Similarly, short positions can be derived from long positions - and vice versa - by mirroring the payoff pattern around the $\mathrm{x}$-axis. In our case of a digital cash-or-nothing option, the payoff pattern of a long call option is congruent to that of a short put option and the payoff pattern of a short call option is congruent to that of a long put option.

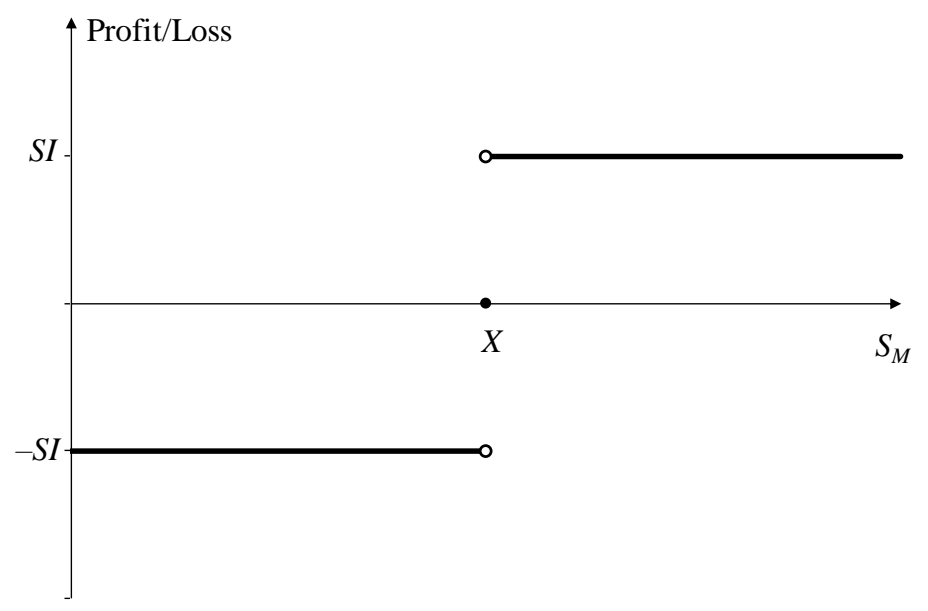

Figure 2. Digital call option profit at maturity. This figure plots the profit (payoff minus initial investment) from a digital call option as a function of the price of the underlying at the option maturity date.

In the digital option design, subjects can, in addition to the information about price and order direction, reveal the strength of their convictions through the amount of money they invest in their digital option quotes (e.g. "I bet 300 cent that the stock price in period eight will exceed 100"). The digital option market thus provides a richer information set than e.g. a futures market. We test whether this more direct revelation (and backing up) of expectations leads to a similar or larger reduction in

\footnotetext{
${ }^{6}$ Since one period in the experimental market can be thought of as corresponding to one day in a real market, no interest was paid on cash holdings, nor was it taken into account in any value calculations. This is reasonable also because one round lasts around 2 hours in real time, making virtually zero any possible real-world interest requirement founded on a time-preference argument.
} 
bubble indicators than the Porter and Smith (1995) design. Our close adherence to their setup in our treatment DO8 - in everything but the choice of derivative instrument - was deliberately chosen to ensure the comparability of our results with their conclusions and with the outcomes of other studies using a similar experimental design.

We later introduced the treatment design DO5/10/15 when we observed that particularly in sessions with experienced traders, subjects in the original treatment seemed to hold out until the option maturity period before they considered trading at prices materially below the peak level. Details and a test of this conjecture are discussed in section 3.3 .

\subsection{Session Design}

Table I gives an overview of the experimental sessions held. We conducted four sessions using the DO8 treatment and three sessions with the DO5/10/15 treatment. All sessions were run using z-Tree (cp. Fischbacher 2007) and structured as follows: The subjects arrived and were seated at computers. The instructions were handed out and read by the subjects (approximately 1 hour). Special care was taken that subjects understood the evolution of the stock's fundamental value (i.e. the fact that the stock had no terminal value was stressed in the instructions and subjects received a table listing the fundamental stock value for every period). The trading institution was explained using detailed examples, and subjects had to correctly answer ten review questions to make sure they had understood the market structure. ${ }^{7}$ In the next step, the $\mathrm{z}$-Tree program was started and all subjects participated in two two-period test rounds to familiarize themselves with the screen layout, interface and market mechanics (app. 0.5 hours). ${ }^{8}$ Following the test rounds, one 15-period experiment was run (app. 1.5 hours), after which the subjects filled in a questionnaire on their screens (app. 0.25 hours), which is reprinted in Table A. 1 in the appendix. This treatment was followed by a lunch break and by a second 15-period experiment (with the same treatment design, but with starting cash and stock inventories that varied for some subjects), once again followed by the subjects filling in the (same) questionnaire. After this, subjects were asked into an extra room, where they received their payment anonymously. ${ }^{9}$

\footnotetext{
${ }^{7}$ A translation of the instructions is available in an online appendix.

${ }^{8}$ Subjects participating in the DO8 treatment could trade a digital option during period 1 of the test round, which expired at the end of period 1. In period 2, the option market was closed. Participants of the DO5/10/15 treatment could trade options in both test periods; these options expired at the end of period 1 and of period 2, respectively.

${ }^{9}$ Most similar studies play each round on a different day, which gives subjects time to recuperate and reflect on the task they are faced with (an exception is Haruvy et al. (2007), who play three rounds in one day). We chose not to follow this pattern mainly because we wanted to ensure that all subjects would return for the repeat rounds and that the time in which subjects could discuss the experiment would be minimized. Our observations confirmed that subjects were highly motivated to perform well in the repeat round and - having consumed lunch between the first and second rounds - did not appear to lack energy and attention.
} 


\section{Table I}

\section{The Sessions}

Five experiments were conducted at the Karl-Franzens-University Graz, Austria and two at the Alpen-Adria-University Klagenfurt, Austria. All experiments were conducted by the author as the sole experimenter. The treatments differ with regard to the option maturity dates. In DO8, option trading is possible from periods 1 to 8 with all options being settled at the end of period 8. In DO5/10/15 there is option trading from period 1 to 5, from 6 to 10 and from 11 to 15, with options being settled at the end of the last trading period in each interval.

\begin{tabular}{ccccc}
\hline Experiment & Treatment & Date & Location & Number of subjects \\
\hline 1 & DO8 & $11 / 10 / 07$ & Graz & 12 \\
2 & DO8 & $12 / 01 / 07$ & Graz & 12 \\
3 & DO8 & $12 / 17 / 07$ & Graz & 11 \\
4 & DO8 & $12 / 18 / 07$ & Graz & 12 \\
5 & DO5/10/15 & $12 / 19 / 07$ & Graz & 13 \\
6 & DO5/10/15 & $02 / 13 / 08$ & Klagenfurt & 12 \\
7 & DO5/10/15 & $02 / 14 / 08$ & Klagenfurt & 14 \\
\hline
\end{tabular}

The payout consisted of the initial wealth (including a loan of $€ 10$ ), plus any proceeds from stock sales, minus any expenditures for stock purchases, plus dividends received from shares held at the end of each period, minus all investments in options, plus all proceeds from options at their maturity date, minus the loan of $€ 10$ (in each session), plus a $€ 3$ attendance fee (payable once per experiment). A subject's payout function from the experiment thus was (all values expressed in euro):

$$
P=\max \left[0, \sum_{s=1}^{2}\left\{W_{s, t=0}+\sum_{t=1}^{15}\left(S T_{s, t}+d_{s, t} \cdot x_{s, t}-S I_{s, t}+P O_{t=M}^{o \in \mathbb{O}_{s, t=M}}\right)-10\right\}+3\right]
$$

where $s$ is the experimental session, $t$ is the period within a session, $W_{s, t=0}$ is the subject's initial wealth at the beginning of the first period of session $s$ (including the loan), $S T_{s, t}$ is the sum of all proceeds from stock sales minus the total cost for all stock purchases in period $t$ of session $s, d_{s, t}$ is the dividend per share, $x_{s, t}$ designates the number of shares held by the subject at the end of period $t, S I_{s, t}$ is the investment in options entered by the subject in period $t$ of session $s, \mathbb{O}_{s, t=M}$ is the set of options with maturity $M$ in session $s$ held by the subject and $P O_{t=M}^{o \in \mathbb{S}_{s, t=M}}$ is the sum of the payoffs from all options in the set $\mathbb{O}_{s, t=M}$ when $t$ equals the option's maturity $M$, for all members of the set $\mathbb{M}$ (and zero when $t$ is not an option maturity date). The maximum term in the payout function guarantees that subjects cannot make losses exceeding the attendance fee. ${ }^{10}$

\footnotetext{
${ }^{10}$ Of the 86 subjects, 5 would have attained a negative payout value (including the attendance fee) and received a payout of zero.
} 
The subjects were students, mainly recruited in bachelor and master courses in banking, finance and economics. Of the subjects participating in the DO8 (DO5/10/15) treatment, 34\% (12.8\%) had previously participated in laboratory experiments, and $25.5 \%$ (15.4\%) claimed to have participated in previous experiments involving the trading of financial securities in a market setting, though to the best of our knowledge nobody had previously participated in a market experiment of the type introduced in Smith et al. (1988).

\section{Table II}

\section{Initial Trader Portfolios}

The table lists the three different initial endowments of traders. Low-cash portfolios carry a high number of shares and vice versa. Each portfolio is complimented by a $€ 10$ loan, repayable at the end of the experiment. All portfolios have equal fundamental value.

\begin{tabular}{ccccc}
\hline Portfolio type & $\begin{array}{c}\text { Initial stock } \\
\text { (number of shares) }\end{array}$ & $\begin{array}{c}\text { Initial cash } \\
(€)\end{array}$ & $\begin{array}{c}\text { Loan } \\
(€)\end{array}$ & $\begin{array}{c}\text { Expected Earnings } \\
(€)\end{array}$ \\
\hline A & 1 & 9.45 & 10.00 & 13.05 \\
B & 2 & 5.85 & 10.00 & 13.05 \\
C & 3 & 2.25 & 10.00 & 13.05 \\
\hline
\end{tabular}

For the test rounds, subjects received endowments of cash from a discrete, integeronly uniform distribution over the interval [225, 945] (in cent) and of stock from the same distribution over [1,3] (in units). For the experiments, each trader received one of three starting portfolios of cash and stock, each of which carried an expected value of $€$ 13.05. These portfolios are shown in Table II and are the same as the endowments in the futures treatment of Porter and Smith (1995) (Table 2, p. 517). Endowments were reinitialized after each session, following the above distributions in case of the test rounds. In the real experiments, endowments were reinitialized following a pattern that ensured the maximum number of differing endowment combinations over both rounds, ${ }^{11}$ subject to the constraint that the average subject received 2 shares and $€ 5.85$ in cash. The two test rounds did not count toward the payout. The expected earnings per subject participating in an experiment comprising two sessions were $€ 29.10$ (including the show-up fee of $€ 3$ ). The period length in the test rounds varied between five and six minutes, the period length in the experiments between four and five. ${ }^{12}$

Subjects' information sets included the number and identity of the subjects, the current best bid and ask in the stock market, their own outstanding stock quotes, and all outstanding option quotes (composed of the winning condition and the amount invested by the offerer). In addition to this information, their screens displayed their

\footnotetext{
${ }^{11}$ That is, some subjects who had received A in round one would get A in round two, some would get B, and some C, with analogous patterns for subjects who had received endowments $\mathrm{B}$ and $\mathrm{C}$ in round one.

${ }^{12}$ Similar to Porter and Smith (1995), we increased the trading time in periods where both the derivative and the spot market were open.
} 
current stock and cash holdings, the period number, the time remaining until the end of the period, and the last stock and option transaction price. Each trader also saw a table listing her past stock transactions (period and price) as well as the options she currently held (winning condition and possible payoff). Traders could submit and cancel quotes in the stock and option markets at any time, subject to no-short-sale and no-margin-buying constraints (excluding the loan of $€ 10$ ). Option quotes that had found a counterparty and had thus been transformed into a binding contract were uncancelable. $^{13}$

In the stock market, subjects could enter new bids (asks) if they improved the current highest (lowest) outstanding offer to buy (sell). They could also buy (sell) a share at the prevailing ask (bid) price by clicking a button labeled "Buy at market price" ("Sell at market price"). In the option market, subjects could submit new option quotes, with their investment bounded from above by their cash holdings. Immediately upon entry, new quotes were checked against existing quotes to determine whether there existed any conflicts. If the new quote conflicted with an outstanding old quote, they were matched and converted into option contracts. The matching was processed to favor the trader posting the newest quote. In other words, quotes that bet on prices lower (higher) than the specified strike price were matched against the conflicting quote with the highest (lowest) price first. Each stock transaction led to the share of stock being transferred from the seller's to the buyer's inventory and cash matching the transaction price being transferred from buyer to seller. In an option transaction, nothing happened if the new quote did not conflict with any outstanding quotes. If there was a conflict, a cash amount corresponding to each counterparty's investment in the newly-formed option was immediately deducted from subjects' inventories to prevent bankruptcy problems. Only when the options reached maturity was their outcome decided and the sum of the investments paid to the subject holding the option that was in the money. In the case where the option matured at the money, each counterparty's investment was returned. $^{14}$

Any transaction in the stock or option market triggered the computer to check whether all outstanding orders were still feasible (e.g. that the subject posting a sell order in the stock market still had a share in her inventory, or that a subject posting a purchase order still had enough cash to fill that order). Unfeasible orders in the stock market were deleted. In the option market the investment amount of each outstanding order was changed to the minimum of the posting subject's cash holdings and the investment amount before the transaction triggering the feasibility check. This ensured that all orders visible in the market could at all times actually be filled by the subjects posting them.

\footnotetext{
${ }^{13}$ See Crowley and Sade (2004) for a study analyzing the effect of permitting the cancellation of orders on trading volume and prices in a double auction environment.

${ }^{14}$ This happened in $0.85 \%$ of all cases. More specifically, $0.74 \%$ of all option contracts in the DO8 treatment and $1.02 \%$ of the DO5/10/15 treatment options were found to be at the money at maturity.
} 


\section{Experimental Results}

\subsection{Measures of Bubble Severity in Spot Market Prices}

A large number of measures documenting bubble extent and severity can be found in the literature (e.g. Ackert et al. 2006, King 1991, King et al. 1993, Noussair and Tucker 2006, Porter and Smith 1995, Smith et al. 1988, Van Boening et al. 1993). In the interest of comparability, we calculate three relevant and frequently reported measures both for our experimental results and for two earlier studies employing treatment designs based on Smith et al. (1988). ${ }^{15}$ A higher value of any variable is associated with a bubble of larger magnitude. The first of the three measures reported in Table III is the Amplitude of a bubble, which gives an indication of the magnitude of peak-to-trough deviations of market prices from the fundamental value. Amplitude $=\max \left[\left(P_{t}-f_{t}\right) / f_{l}\right]-\min \left[\left(P_{t}-f_{t}\right) / f_{l}\right]$, where $P_{t}$ equals the mean transaction price in period $t$ and $f_{t}$ is the fundamental value in period $t$. Second, the Duration measures the temporal length of a bubble. Duration $=\max \left(m: P_{t}-\right.$ $\left.f_{t}<P_{t+1}-f_{t+1}<\ldots<P_{t+m}-f_{t+m}\right)$. This formula defines as the duration of a bubble the longest uninterrupted interval during which the deviation of mean period prices from period fundamental values increases. The third measure, Turnover, documents the trading volume in the stock market. It is defined as Turnover $=\left(\Sigma_{t} q_{t}\right) / q$, where $q_{t}$ is the number of stock transactions in period $t$, and $q$ (sometimes referred to as TSU, or Total Stock of Units) is the total number of shares in the experimental market. Note that in a market with common knowledge about the rationality of all traders, risk-aversion would be the only factor motivating (limited) trading. ${ }^{16}$ For this reason, high Turnover can be considered indicative of a price bubble.

\footnotetext{
${ }^{15}$ More bubble measures and transaction-level data are available from the author upon request.

${ }^{16}$ In this case, shares of the risky stock would be transferred from subjects with a higher risk-aversion to subjects with lower risk-aversion. Once a Pareto optimal allocation has been attained, trading would cease.
} 
Table III

\section{Bubble Measure Results}

This table compares bubble measures reported in the literature for experimental asset markets. Our own results are printed in bold at the bottom of each block. All numbers reported in columns 2-4 are means over all markets conducted with the stated treatment and level of experience. The last column lists the number of rounds the reported measures are the mean of, for each level of experience. The duration measure cannot be calculated for all studies due to a lack of reported data.

\begin{tabular}{llcc}
\hline Measure & \multicolumn{2}{c}{ Experience } & \\
\cline { 2 - 3 } Article / Treatment & None & Once & $\mathrm{n}$ \\
\hline Amplitude & & & \\
Ackert and Church (2001) - Baseline & 1.07 & 0.52 & $3 ; 2$ \\
- Non-business & 1.21 & 0.67 & $3 ; 2$ \\
Porter and Smith (1995) - Baseline & 1.53 & 0.86 & $10 ; 8$ \\
-Futures & 0.92 & 0.60 & $3 ; 2$ \\
Smith et al. (2000) - Baseline & 1.39 & 0.93 & $6 ; 3$ \\
Van Boening et al. (1993) - Call auction & 1.61 & 1.18 & $2 ; 2$ \\
This article - DO8 & $\mathbf{1 . 2 4}$ & $\mathbf{0 . 9 3}$ & $\mathbf{4 ; 4}$ \\
-DO5/10/15 & $\mathbf{1 . 5 7}$ & $\mathbf{1 . 0 2}$ & $\mathbf{3 ; 3}$ \\
Duration & & & \\
Ackert and Church (2001) - Baseline & 9.33 & 2.50 & $3 ; 2$ \\
- Non-business & 9.00 & 5.00 & $3 ; 2$ \\
Porter and Smith (1995) - Baseline & 10.15 & 4.75 & $10 ; 8$ \\
-Futures & 10.00 & 5.50 & $3 ; 2$ \\
This article - DO8 & $\mathbf{1 1 . 0 0}$ & $\mathbf{6 . 7 5}$ & $\mathbf{4 ; 4}$ \\
- DO5/10/15 & $\mathbf{1 1 . 0 0}$ & $\mathbf{7 . 0 0}$ & $\mathbf{3 ; 3}$ \\
Turnover & & & \\
Ackert and Church (2001) - Baseline & 2.45 & 1.05 & $3 ; 2$ \\
- Non-business & 2.02 & 0.85 & $3 ; 2$ \\
Porter and Smith (1995) - Baseline & 5.49 & 2.98 & $10 ; 8$ \\
-Futures & 6.85 & 2.63 & $3 ; 2$ \\
Smith et al. (2000) - Baseline & 5.18 & 3.20 & $6 ; 3$ \\
Van Boening et al. (1993) - Call auction & 3.08 & 1.68 & $2 ; 2$ \\
This article - DO8 & $\mathbf{6 . 3 1}$ & $\mathbf{4 . 2 2}$ & $\mathbf{4 ; 4}$ \\
- DO5/10/15 & $\mathbf{5 . 6 8}$ & $\mathbf{4 . 7 9}$ & $\mathbf{3 ; 3}$ \\
\hline
\end{tabular}

Table III lists the results for these bubble measures for four treatments from previous studies in the literature and for the two treatments of the present article. The Amplitude measure demonstrates that the digital option treatments do not produce better results than the Smith et al. (1988) baseline design or than experiments with non-business-major student subjects (designated "Non-business" in Table III). The 
only design which consistently yields higher-altitude bubbles is a treatment from Van Boening et al. (1993) using call auctions. The Porter and Smith (1995) futures treatment, conversely, is associated with a considerably smaller bubble Amplitude. The two measures of Duration and Turnover paint a similar picture. Taken together, our hypothesis that trading in a digital option market reduces the extent of bubbles finds no support. As will be discussed below, the reason for this failure of a nonredundant market to lead to an increase in informational efficiency has its roots in the same mechanism that leads to bubbles in the first place: (Some) subjects do not condition on fundamental value.

\subsection{Analysis of Market Efficiency}

Given the bubble measure evidence, we decided to focus our efforts on trying to find the reason for the option market's failure in aiding subjects' expectation formation process. Table IV lists statistics on the informational efficiency of stock and option prices. If our experimental markets had been efficient, they would have exhibited a number of characteristics with regard to the interrelation of the time series of stock and option prices. First, the mean stock price per period would have correlated perfectly positively with the fundamental value of the stock. Second, the mean option (strike) price per period in the DO8 treatment would not have been correlated with the stock price or with the stock's fundamental value, since the rational option price in this treatment has a variance of zero, as it is fixed at 192 cent. In the DO5/10/15 treatment, a similar argument applies when viewing the three subintervals consisting of periods 1-5, 6-10 and 11-15 separately. Furthermore, it is easy to show that over the entire trading horizon, the mean period standard deviation of option prices in the DO5/10/15 treatment is bounded from above by $120 .{ }^{17}$

The results reported in Table IV depart widely from this efficient yardstick. Stock and option prices are substantially correlated, thus lending little weight to the notion of option market efficiency. An even stronger sign of the observed inefficiency is provided by the option standard deviation results. The mean option price standard deviation in the DO8 (DO5/10/15) treatment - which should be zero (smaller than 120) - varies between 19.5 and 73.3 (135.2 and 167.7), an interval that does not even contain the efficient figures. ${ }^{18}$ Note that Figure 4 provides plots of the stock and option prices in all markets.

\footnotetext{
${ }^{17}$ Since the distribution of option transactions between different periods is indeterminate, the price variance of an option market populated only with fundamental value traders is also indeterminate. Its upper bound can be arrived at by exploring the transaction pattern that, while still informationally efficient, maximizes the observed option price standard deviation. This pattern is characterized by an equal number of option transactions in the intervals of periods 1-5 and periods 11-15, with no transactions in periods 6-10. Assuming that all transactions take place at the efficient prices of 264 and 24 in periods 1-5 and 11-15, respectively, the resulting standard deviation would be 120 .

${ }^{18}$ The standard deviation reported in Table IV was calculated as the average session standard deviation of all transaction prices within each market.
} 
Table IV

\section{Market Efficiency Statistics}

This table lists the mean correlation of mean period prices by round, over all sessions, by treatment. Also included is the standard deviation of option prices.

\begin{tabular}{|c|c|c|c|c|c|c|c|c|c|}
\hline \multirow[b]{2}{*}{ Measure } & \multicolumn{3}{|c|}{ DO8 } & \multicolumn{3}{|c|}{ DO5/10/15 } & \multicolumn{3}{|c|}{ Both } \\
\hline & 1 & 2 & All & 1 & 2 & All & 1 & 2 & All \\
\hline $\begin{array}{l}\text { Correlation Stock - } \\
\text { Option }\end{array}$ & 0.81 & 0.66 & 0.73 & $0.60^{*}$ & $0.55^{*}$ & $0.58^{*}$ & 0.87 & 0.76 & 0.80 \\
\hline $\begin{array}{l}\text { Correlation Stock - } \\
\text { Fundamental }\end{array}$ & 0.31 & 0.86 & 0.62 & -0.04 & 0.75 & 0.36 & 0.16 & 0.81 & 0.52 \\
\hline $\begin{array}{l}\text { Correlation Option - } \\
\text { Fundamental }\end{array}$ & -0.91 & -0.51 & -0.69 & $-0.30^{*}$ & $-0.14^{*}$ & $-0.22^{*}$ & -0.57 & 0.04 & -0.28 \\
\hline $\begin{array}{l}\text { Option price standard } \\
\text { deviation }\end{array}$ & 73.3 & 56.2 & 59.7 & 135.2 & 167.7 & 151.4 & 99.8 & 104.0 & 96.4 \\
\hline
\end{tabular}

* Average mean correlation of stock and option prices over the three intervals consisting of periods 1-5, 6-10 and 11-15, over all sessions.

Before proceeding to more advanced analyses, we seek an explanation for these inefficiencies in the answers from our questionnaire (for more details see also Table A.1 and the discussion in the appendix). Our sixth question asks whether subjects felt that the option market had helped them in determining how much they would be willing to pay for the stock. The mean answer (on a scale from zero to four, where zero corresponded to "Not at all" and four to "Very much") is 1.362 (1.404) for the inexperienced (once experienced) subjects in the DO8 treatment and 1.513 (1.333) for the DO5/10/15 treatment, indicating that subjects do not find the option market to be very helpful in forming expectations about future prices.

Our first intuition was that the instructions regarding the option market are unclear. This suspicion is refuted by the relatively high mean answer values on question nine, inquiring how easy it had been for the subject to understand the market mechanism and to form a strategy (scaled between 0, or "Hard" and 4, or "Easy"), which are 2.596 (2.702) for DO8 and 2.564 (2.795) for DO5/10/15, and by the mean answers on question ten, asking how easy it had been for the subject to understand the written and oral instructions, which are 3.170 (3.404) for DO8 and 3.282 (3.462) for $\mathrm{DO} 5 / 10 / 15$.

\subsection{Adaptive Expectations and Trading Behavior}

Feeling confident that subjects understand the task, we next focus our attention on the way they form expectations. Figure 3 plots the price deviations of mean transaction prices from the fundamental prices induced by the expected subsequent divi- 
dend payments, for each treatment and period. ${ }^{19}$ All our price processes follow paths similar to, but certainly no more efficient than those reported for the baseline series in the literature. Over the course of a round, prices rise from close to the dividend holding value to levels significantly exceeding this fundamental benchmark, ${ }^{20}$ and then crash back to levels close to the stock's intrinsic value during the later periods. Experience improves (i.e. lowers) most measures of the extent of the price bubbles (see Table III).

Soliciting forecasts, Haruvy et al. (2007) find that subjects in this kind of asset market initially expect constant transaction prices over time. Adapting their expectations during a session, they then come to expect a continuation of observed trends. In repetitions of the market experiment, subjects exhibit myopic behavior when basing their behavior on past price patterns. Anticipating the downturn in prices, but not the feedback their (and their fellows') actions have on the market, they induce prices to peak earlier, thus attenuating and finally eliminating the bubble over multiple repetitions of the market.

\footnotetext{
${ }^{19}$ We used feedback from subjects during the experiment and from the questionnaires to remove outliers that could be clearly identified to have been caused by errors in data entry. Specifically, we removed one outlier from period 8 in the first session of experiment 4, one from the first (period 9) and two from the second session (both period 15) of the fifth experiment and one each from the two sessions (period 7 and period 1, respectively) of the sixth experiment. This corresponds to 0.429 such outliers per session, or 0.029 per period. The results do not change materially if these outliers are retained.

${ }^{20}$ A $t$-test of the mean session price deviations from fundamental value being smaller or equal to zero yields a $p$-value $<0.001$ overall, for both treatments, and for both levels of experience.
} 


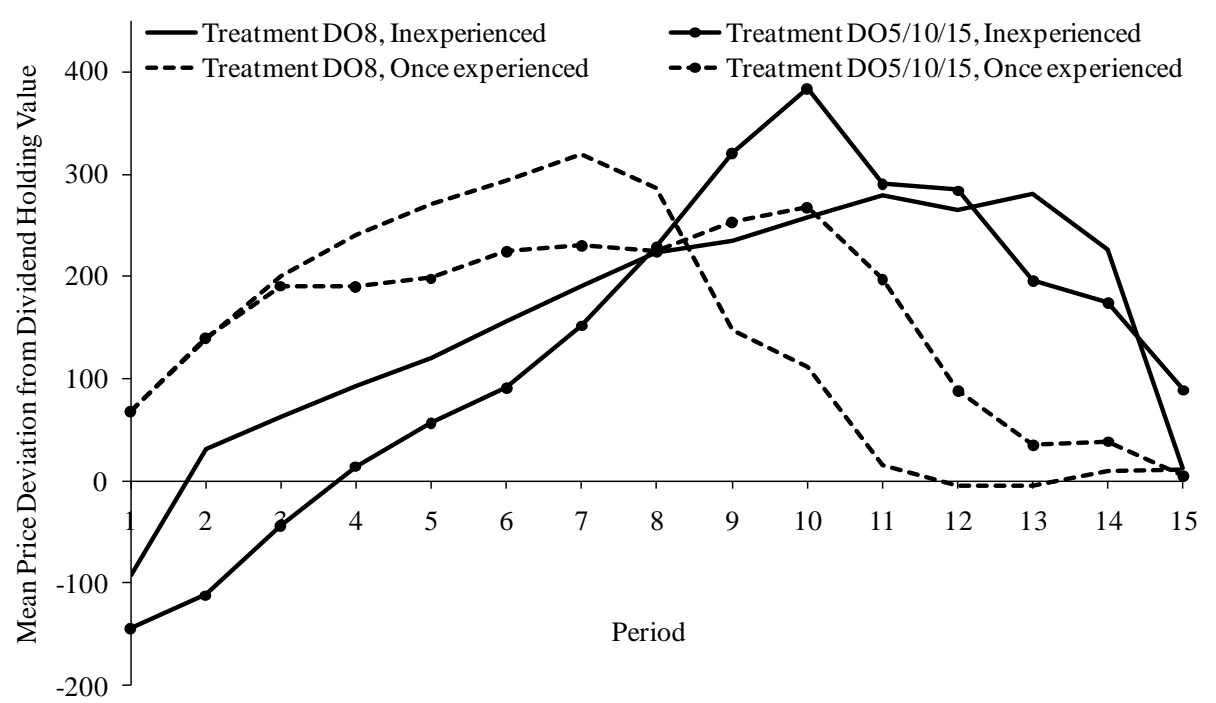

Figure 3. Mean stock price deviation from dividend holding value. The five plots show, for each treatment and two levels of experience, the mean over all sessions of the mean stock price per period. Inexperienced subjects have never participated in an experiment of this type and once experienced subjects are the same individuals in the second trading session. There were no periods without trade.

The following observations with regard to Figure 3 show that our findings similarly support such a mechanism of learning by observation. We find from our questionnaires and from conversations with our experimental subjects that participants in our experiment are surprised by the trajectories prices follow during the first session (the two solid lines in Figure 3), which in all of our sessions conform closely to the typical bubble-and-crash pattern. Consistent with the Haruvy et al. (2006) argument, subjects then seem to 'learn to bubble and crash' from this first session. More specifically, subjects learn that the session starts with strongly positive price developments, followed by a price downturn towards the end. In anticipating this now familiar pattern, they strengthen the pattern of large positive price changes in the early periods and hasten the subsequent return of prices to levels near fundamental value. As Figure 3 shows, the mean price paths of the once experienced treatments up to period 7 are strictly above those of the inexperienced treatments. Also, in the experienced treatments, prices are closer to dividend value than in the inexperienced treatments from period 11 onwards.

The same pattern can be observed in Porter and Smith (1995) (Figure 1, p. 511), and even Smith et al. (1988) already noted that their sessions 26 and 28x (both using the same subjects) conform to this pattern. If, by participating in the first period, subjects had improved their understanding of the market and recognized that prices at the end of the session tended toward fundamental value (an alternative hypothesis sometimes found in the literature, cp. e.g. Ackert and Church 2001, p. 18), one 
would assume that the crash should occur earlier - as it does - and that the run-up to the bubble should be dampened - which it is not.

There is some evidence that not all participants fall prey to such failures of economic reasoning. We proceed by identifying different groups of subjects with regard to their trading strategies. Following the procedures laid down in Haruvy and Noussair (2006), we categorize subjects' behavior into three types. Feedback traders follow a momentum strategy, buying after price increases and selling after price decreases. Speculators 'ride the bubble' until near the end of the market, where they realize that speculation on an upward price movement is unlikely to be profitable very late in a market and start to sell, which precipitates the crash. Passive investors, finally, trade based on the present period's fundamental value, buying at prices below and selling at prices above the dividend holding value. We find that feedback traders make up $42.0 \%$ (39.4\%) of all inexperienced (experienced) subjects, $25.7 \%$ (26.0\%) fall into the category of speculators, and $26.8 \%$ (32.4\%) can be designated passive investors. ${ }^{21}$ Note that our results with inexperienced subjects are very close to the proportions found by Haruvy and Noussair (2006) for their No Short Sales (NSS) treatment, which are $43.5 \%, 29.6 \%$ and $26.8 \%$, respectively. In other words, the possibility of trading in a digital option market does not seem to influence participants' overall strategies in the market of the underlying.

We next try to find interrelationships between subjects' types and their actions in the option market, in order to deepen our understanding of the factors driving the price deviations in stock and option markets. In particular, we perform extensive regression, correlation and hypothesis tests of links between subjects' scores with regard to the three categorizations and their activity in both markets. Unfortunately, we find that none of the three groups is clearly more active than the others and that none exhibits trading patterns which deviate clearly from those of the others.

Despite the lack of direct evidence regarding the factors driving prices in the option markets, we observe that both option quotes and transactions in the option market are disconnected from fundamental value and closely follow contemporaneous prices in the stock market (see Figure 4). This close link between irrationally high contemporary stock and option prices is present in most of our sessions, which at least partly answers the question regarding the option market's helpfulness from above. The option market cannot be informative for the expectations formation of our subjects, because its prices are equally biased as are those of the stock market.

\footnotetext{
${ }^{21}$ Following the categorization algorithm outlined in Haruvy and Noussair (2006), 5.5\% (2.3\%) of all subjects could not be clearly assigned to any of the three categories.
} 


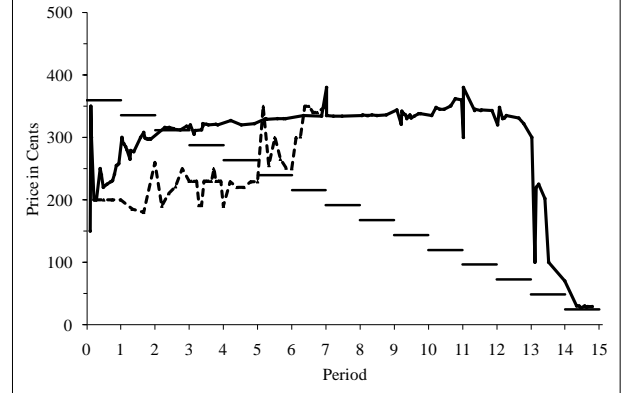

(a) Exp. 1, Inexperienced, DO8

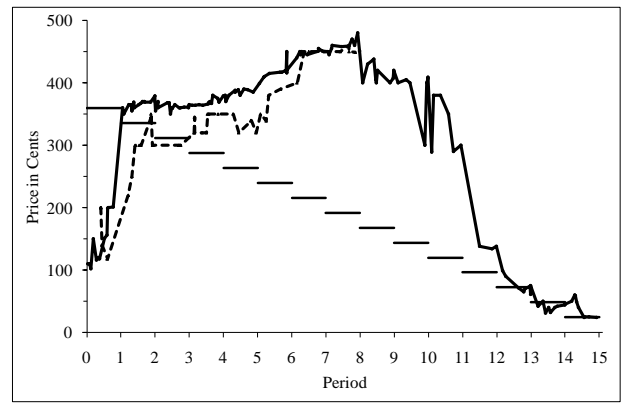

(c) Exp. 2, Inexperienced, DO8

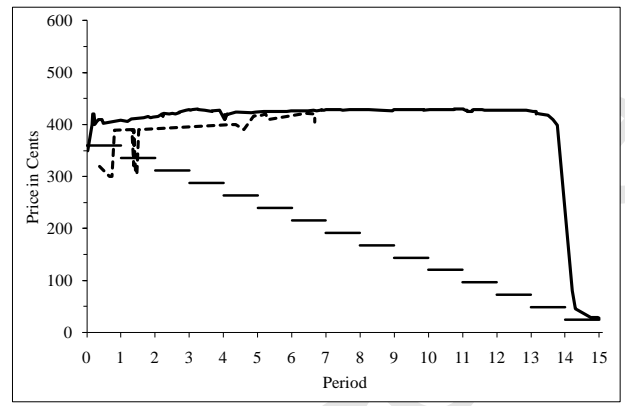

(e) Exp. 3, Inexperienced, DO8

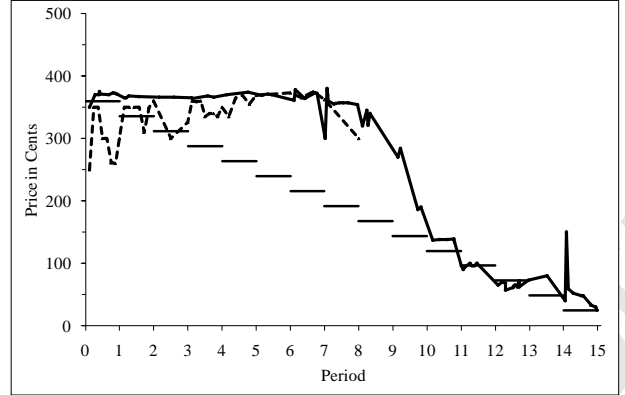

(b) Exp. 1, Once experienced, DO8

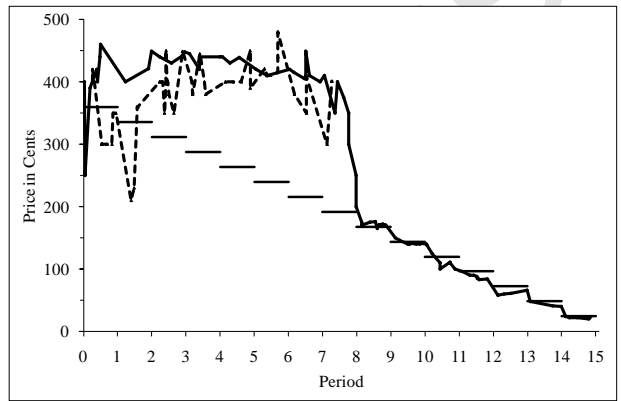

(d) Exp. 2, Once experienced, DO8

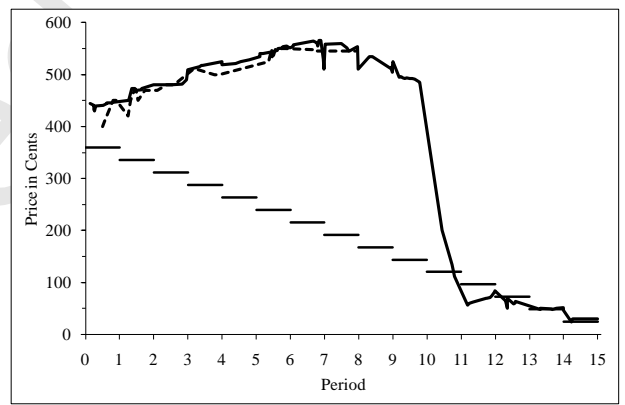

(f) Exp. 3, Once experienced, DO8

Figure 4. Price plots of experimental sessions. The figure plots the stock price (solid line), option price (broken line), and fundamental value (stepwise decreasing function) in all sessions of the experimental schedule. 


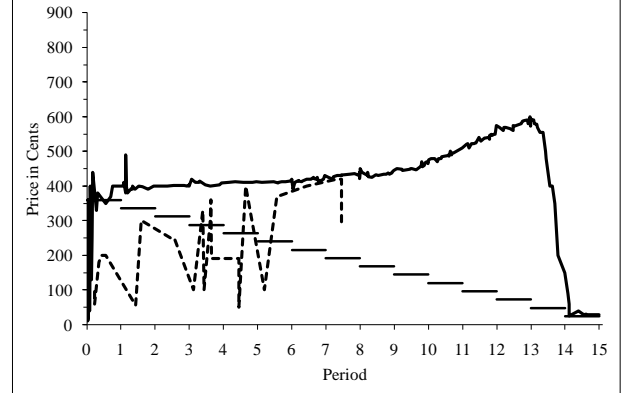

(g) Exp. 4, Inexperienced, DO8

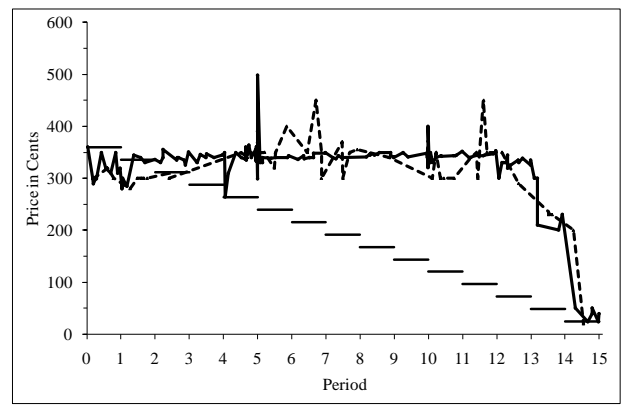

(i) Exp. 5, Inexperienced, DO5/10/15

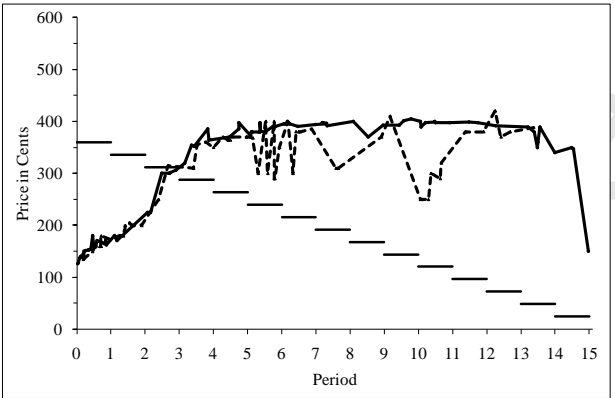

(k) Exp. 6, Inexperienced, DO5/10/15

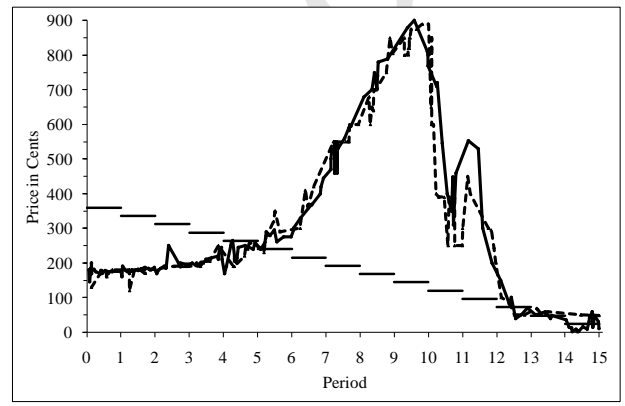

(m) Exp. 7, Inexperienced, DO5/10/15

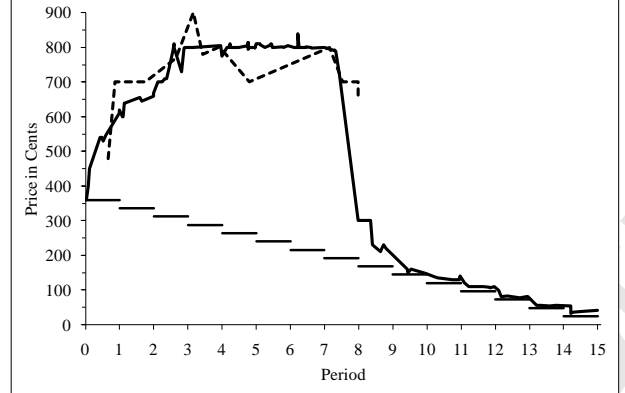

(h) Exp. 4, Once experienced, DO8

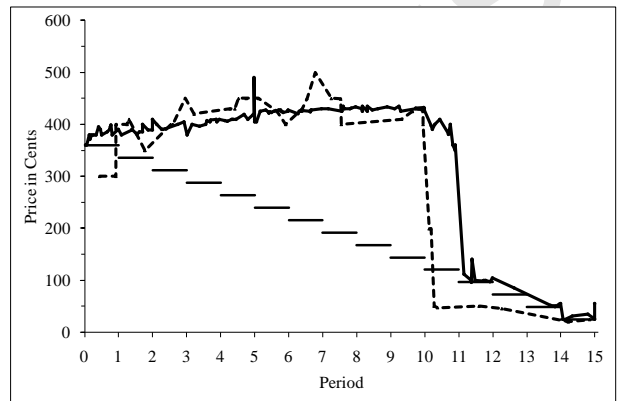

(j) Exp. 5, Once experienced, DO5/10/15

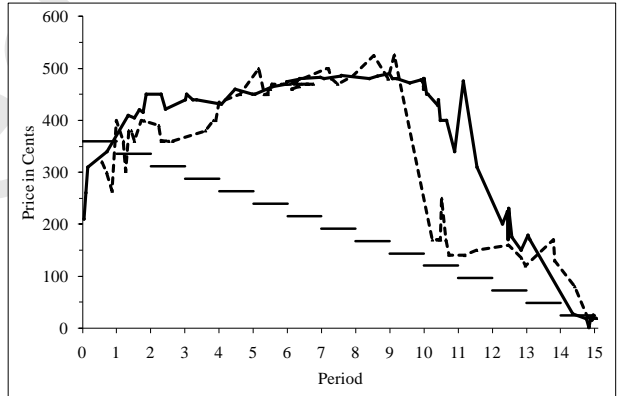

(1) Exp. 6, Once experienced, DO5/10/15

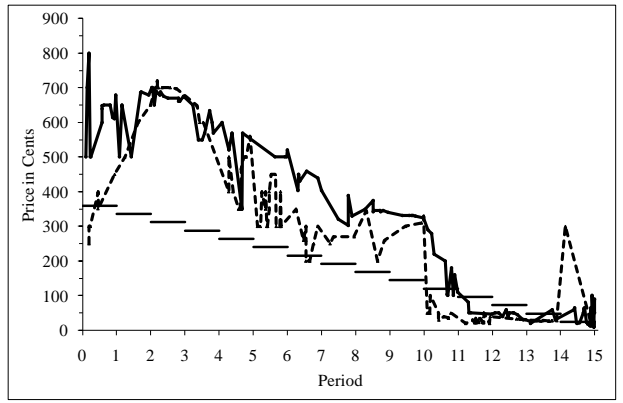

(n) Exp. 7, Once experienced, DO5/10/15

Figure 4 cont. Price plots of experimental sessions. The figure plots the stock price (solid line), option price (broken line), and fundamental value (stepwise decreasing function) in all sessions of the experimental schedule. 
Another manifestation of the bounded rationality of our traders is the apparent structural break around the eighth period in the DO8 treatment. This break is especially pronounced in the sessions with experienced traders (see Figure 4). We gained the impression that prior to period 8 , subjects' attention with regard to the stock price is focused on the levels of their options' strike prices. This is supported by a substantial number of questionnaire replies which suggest that subjects try to manipulate the stock price around option maturity dates to secure a positive payoff from their option investments (see the discussion in section 5.1 of the Appendix). In other words, approaching period 8 , traders seem to try to move their options into the money by adjusting the transaction prices they quote and accept in the stock market. Only once the option outcomes have been decided do they let the fundamental dividend value reenter their stock price expectations formation process. We find some corroborating evidence for this behavior in call option transaction data. The number of call options entered by a subject and the number of stocks bought by a subject in the same period is moderately positively correlated (coefficient of $0.172, p$-value of 0.010). So is the total number of call options entered and the number of stocks bought over the fifteen periods of a market (coefficient of 0.151, $p$-value of 0.049). No similar relationships are found for put options or stock sales. ${ }^{22}$ Finally, note that the decline in stock prices begins no sooner than period eight in any of the sessions belonging to the first four experiments.

To investigate this apparent change in the expectations formation regime of our subjects, we perform a test for breakpoints in our data. Employing the methodology described in Bai and Perron (2003), we use a regression of the time series of stock price deviations from fundamental value on a constant and constrain the number of breakpoints to one. We find that breakpoints are identified in periods $10,8,10$, and 8 in sessions $1,2,3$, and 4 with experienced subjects, respectively. While this result conforms to our expectations, the breakpoints with inexperienced subjects are identified in periods $5,2,5$, and 7 , respectively, thus yielding no clear pattern. Nonetheless we based the DO5/10/15 treatment on these perceived breakpoints, designing it to test whether more frequent option maturity dates would hasten the return to fundamental values. To our disappointment, this alternative treatment removed the tendency of the structural change to take place between the eighth and tenth period, but did not improve price efficiency overall. ${ }^{23}$

As a final contribution to our description of trading behavior in concurrent stock and digital option markets, we provide information on trading volume. The mean trading volume in each period of the stock market is plotted in panel (a) of Figure 5. If stock turnover is regarded as a bubble measure, experience clearly leads to a more efficient market. In 26 out of 30 cases, the mean turnover in the stock market decreases from the inexperienced treatment to the once experienced treatment. Assuming a binomial distribution with a probability of success of 0.5 , a random draw would

\footnotetext{
${ }^{22}$ We thank an anonymous referee for suggesting this line of analysis.

${ }^{23}$ In the three DO5/10/15 sessions, breakpoints are identified in periods 5, 3, and 6 for inexperienced subjects and in periods 11,2 , and 11 .
} 
yield this result with a probability of less than $10^{-5}$. Interestingly, all four cases where mean turnover increases from the inexperienced to the experienced market occur in the DO5/10/15 treatment. Contrary to our conjecture that more option maturity times would increase the efficiency of the market, this measure would indicate that the opposite is the case.

We also investigate whether the stock price manipulation around option maturity dates that was mentioned above is apparent in our trading volume data. Unfortunately, this is not the case. In a number of tests, stock market trading volume exhibits no remarkable patterns around option maturity dates (period 8 in the DO8 treatment and periods 5, 10, and 15 in the DO5/10/15 treatment). The results in panel (b) similarly show no apparent regularity in the number of option transactions over time.

Note that the number of transactions is generally lower in the option than in the stock market. However, this observation does not suggest a lower overall importance of option trading. Due to the non-linear nature of the payoff function, the possible return variance in these markets is considerable. The option investments of the average trader in period $8(5 / 10 / 15)$ of the DO8 (DO5/10/15) treatment constitute $26.6 \%(22.3 \% / 20.0 \% / 25.3 \%)$ of her initial wealth.

We furthermore find that the number of unfilled stock quotes is not significantly affected by experience level, while the number of transactions is significantly smaller for experienced subjects, with a $t$-test $p$-value of 0.000 both for the DO8 sessions and the pooled dataset (but not for the DO5/10/15 session, with a $p$-value of 0.235 ). This is evidence that subjects are no less active in experienced sessions, but may be less willing to accept unattractive prices (i.e. they possibly negotiate harder). ${ }^{24}$

\footnotetext{
${ }^{24}$ Figure A.1 in the appendix presents the volume of unfilled stock and option quotes in the same format as Figure 5.
} 


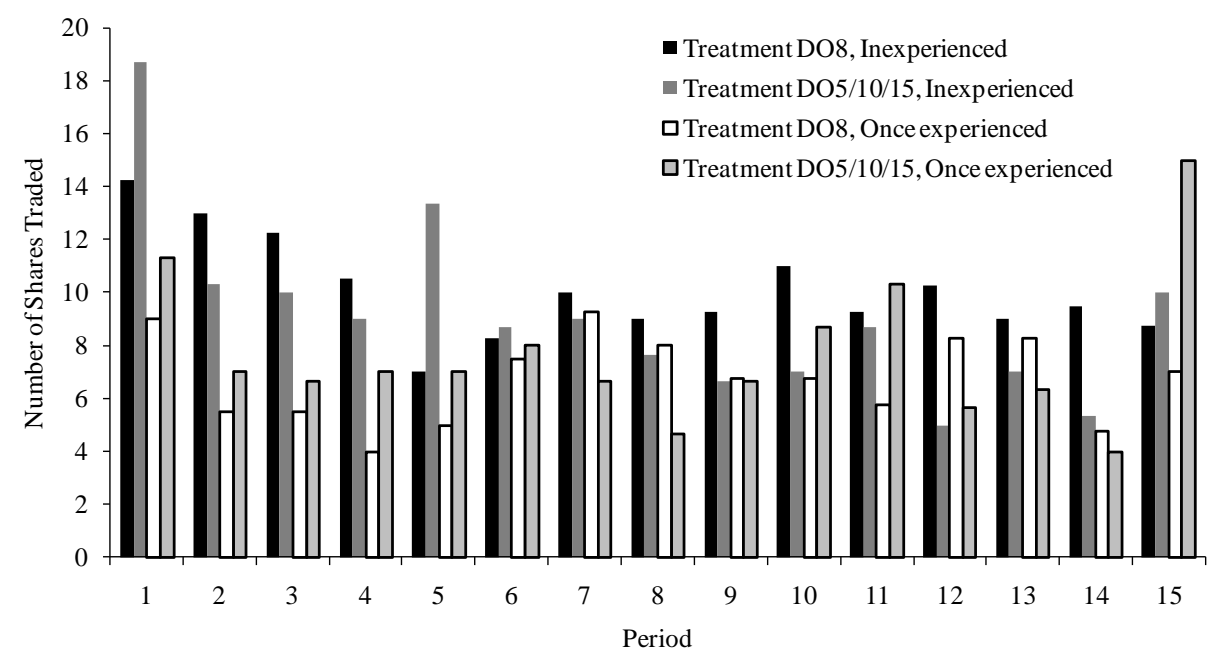

(a)

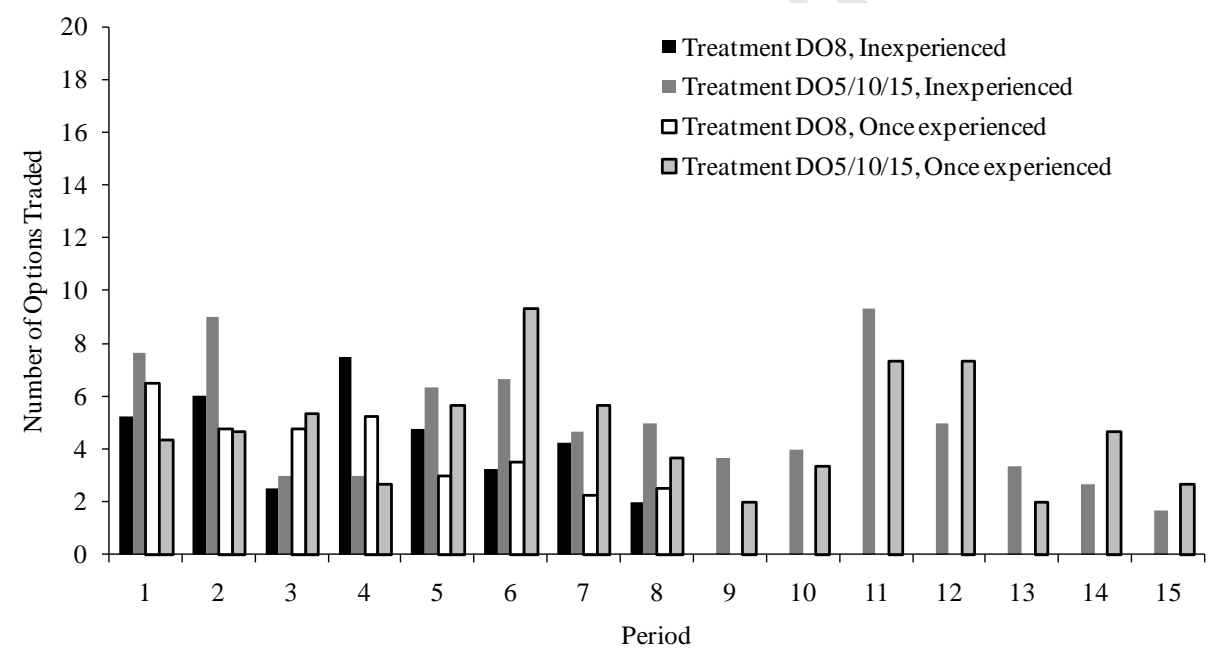

(b)

Figure 5. Mean trading volume. The two graphs show, for each treatment and two levels of experience, the mean trading volume in the stock market (a) and option market (b) over all sessions. Inexperienced subjects have never participated in an experiment of this type and once experienced subjects are the same individuals in the second trading session. 


\section{Conclusion}

In this article, we report the results of double auction stock market experiments in line with Smith et al. (1988), augmented by the possibility of trade in an option market. Our hypothesis was that trading in the option market induces subjects to form expectations about future prices at an early point in the experiment and to use these expectations to derive a spot price expectation closer to fundamental value by backward induction.

We find no support for our hypothesis, as the extent and form of the observed stock price bubbles are comparable to those of earlier baseline experiments documented in the literature. We analyze the trading behavior in the stock and option markets and report some preliminary attempts to explain this finding, which are grounded in the bounded rationality of traders. A trader classification as proposed in Haruvy and Noussair (2006) supports the conjecture that a majority of traders does not (sufficiently) condition on fundamental value in their trading decisions for the bubbleand-crash pattern to be attenuated. In line with findings by Haruvy et al. (2007), traders in our markets seem to converge to efficient prices only through a process of myopically adapting their expectations based on observed price patterns in the past. There is a disconnect between our results, which indicate no improvement in informational market efficiency in the presence of digital options, and many other studies that find increased efficiency in spot markets which are complemented by standard options and particularly futures. The reason may lie in the specific form of derivative employed. ${ }^{25}$ Futures contracts (and standard option contracts, conditional on the future price) imply that buyers take possession of the stock, while sellers have to buy the stock before or at the maturity date, which provides the means for hedging and arbitrage. Due to their trinary payoff pattern, hedging with digital options is hardly feasible. There thus seems to be a tradeoff in that digital options may attract more diverse market participants due to their simplicity, yet on the other hand do not provide information of the same quality as standard derivatives contracts due to the less direct link between their price and that of the underlying asset. Furthermore, the discontinuous payoff structure also increases incentives to manipulate the price of the underlying asset around the maturity date where this is possible.

Based on these two findings from our experiments, we caution against placing too much faith in the ability of prediction markets using this type of derivative to induce an increase in spot market price efficiency. This is particularly true in markets where participants have the ability to influence the value of the underlying to a significant degree (as is for example often the case in prediction markets within companies). It is an open - but interesting - question, whether standard options would perform better at increasing informational efficiency in the Smith et al. (1988) market design.

\footnotetext{
${ }^{25}$ We thank an anonymous referee for pointing this out.
} 


\section{Appendix}

\subsection{Translation of the Questionnaire and Discussion of Subjects'Responses}

Table A.1 below provides a translation of and summary statistics on the questionnaire subjects had to fill in after having participated in each 15-period market. The answers on the open questions of the questionnaire are very diverse and in many cases ambiguous, since subjects often do not write complete sentences, leaving the interpretation of the keywords provided up to the reader of the questionnaire. This makes it hard to aggregate the answers to an overall picture. In the interest of providing the maximum amount of information, we nonetheless try to convey the most important findings in this section. We report results at the level of individual questionnaires, which gives us 172 observations (one each for the first and second rounds for the 86 subjects).

Answers on the first two questions, which inquire after subjects' strategy and its change over the course of a round, often describe subjects' actual actions in the experiment (i.e. provide ex post rationalization), not an ex ante strategy that they might have held in their minds at the beginning of a round. More specifically, 36 replies amount to a strategy of trying to buy at low prices and selling at high prices. 24 replies reflect that dividends were the focus of subjects' interest, with 14 replies saying that subjects bought shares with the express motivation of earning dividends. Note that this is in line with studies in the experimental asset market literature which find that subjects seem to overweight dividends in this type of markets, and that dividends play a vital role in bubble formation (e.g., Smith et al. 2000). Another 18 replies indicate a strategy of trading based on fundamental value, while the same number of replies suggest the respondents tried to speculate based on expectations about future price changes. Furthermore, 9 replies in DO8 sessions and 10 in DO5/10/15 sessions state that the respondents tried to manipulate prices in the stock market around the option maturity dates to make sure their options would expire in the money. Five recommend preventing such behavior through the treatment design to improve the experiment.

In reply to the third question on subjects' beliefs about their fellow traders' strategies, 43 say the other subjects acted just like themselves, while 14 don't answer or state that they don't know what their fellow traders' strategy had been. In some cases, observed price pattern are attributed to active planning by the other subjects (e.g., "First drive prices up, then let them crash."), yet most replies just describe what happened in the market, thus not really providing insights into what the responders thought the other subjects' strategy had been.

Regarding questions 10 and 11 on how easy it had been for subjects to understand the instructions and how to improve them (as well as the experiment overall), out of the 172 questionnaires, 64 do not reply to the questions, and 21 explicitly say that the instructions were clear and/or of high quality. Five replies recommend increasing the number and/or length of the training rounds, and another five suggest providing a chart of stock prices. Four replies say the instructions are complex, but that 
the respondents cannot think of a way to simplify them because the subject matter is complex. Three replies recommend giving more time to read the instructions (although subjects had to indicate when they had finished reading the instructions and were ready to move on, thus themselves determining the time they had for reading the instructions) and two replies suggest making the instructions shorter. Two replies stated that bogus price quotes (e.g. an offer to sell for a price of 1000) were distracting, while one reply says the subject found the option market interface confusing and another recommends improving the option market instructions. One reply suggests offering more breaks, another says that the subject was exhausted after the second round. Most of the other replies are either unclear or suggest "improvements" of the experiment which would have conflicted with our research objective (e.g. to tell people before the experiment what the commonly observed price pattern looked like in this kind of markets, or to make it impossible for people to drive prices up too much by letting them short sell). Overall, and in light of the complexity of the experimental task, we consider this feedback to support the notion that the instructions are sufficiently clear to subjects. 
Table A.1

Questionnaire

The questions listed in this table were asked of all participants after each 15-period session. Questions scaled to the numbers $0-4$ carried a caption that had one pole designated with a term similar to "Disagree completely" and the other pole with a designation similar to "Agree completely" and gave subjects 5 possible points between these two poles to choose as their answer ( 0 corresponding to "Disagree completely" and 4 corresponding to "Agree completely"). An " $x$ " in the caption row corresponds to one session of prior experience for the subjects.

\begin{tabular}{|c|c|c|c|c|c|}
\hline \multirow{2}{*}{ Question } & \multirow{2}{*}{ Scale } & \multicolumn{4}{|c|}{ Mean } \\
\hline & & DO8 & DO8x & DO5/10/15 & DO5/10/15x \\
\hline What was your strategy during the experiment? & Open/Text & & & & \\
\hline Did you change your strategy during the experiment and if yes, why? & Open/Text & & & & \\
\hline What do you believe was the strategy of the other subjects? & Open/Text & & & & \\
\hline Do you think that you acted rationally and that you were able to maximize your profit? & $0-4$ & 2.149 & 2.468 & 2.154 & 2.103 \\
\hline Did you at any time mistype something? If yes, please describe briefly when and how this mistake occurred! & Open/Text & & & & \\
\hline Did the option market help you gauge how much you would be willing to pay for the stock? & $0-4$ & 1.362 & 1.404 & 1.513 & 1.333 \\
\hline Compared to the average player, how successful do you think you were? & $0-4$ & 1.787 & 2.021 & 1.872 & 1.692 \\
\hline What do you think is the reason for your having performed better/worse? & Open/Text & & & & \\
\hline How easy was it for you to understand the market mechanism and prepare a strategy? & $0-4$ & 2.596 & 2.702 & 2.564 & 2.795 \\
\hline How easy was it for you to understand the written and oral instructions? & $0-4$ & 3.170 & 3.404 & 3.282 & 3.462 \\
\hline How could the experiment be made easier to understand and/or what could be improved? & Open/Text & & & & \\
\hline Which studies have you completed or are currently enrolled in? & Open/Text & & & & \\
\hline Your age? & $17-99$ & 25.23 & 25.19 & 24.38 & 24.33 \\
\hline Your sex? & Female/Male & $42.6^{¥}$ & $42.6^{¥}$ & $28.2^{¥}$ & $28.2^{¥}$ \\
\hline Highest level of education completed? & * see below & & & & \\
\hline Is this your first laboratory experiment? & Yes/No & $66^{\dagger}$ & - & $87^{\dagger}$ & - \\
\hline How good would you say is your knowledge of finance and capital markets? & $0-4$ & 2.234 & 2.234 & 2.103 & 2.077 \\
\hline Have you traded stock in the past? & Yes/No & $48.9^{\dagger}$ & $48.9^{\dagger}$ & $41^{\dagger}$ & $41^{\dagger}$ \\
\hline Have you traded options in the past? & Yes/No & $12.8^{\dagger}$ & $12.8^{\dagger}$ & $7.7^{\dagger}$ & $7.7^{\dagger}$ \\
\hline How often have you participated in a similar experiment involving trading of stock in a market? & Number & 0.255 & 1.255 & 0.154 & 0.615 \\
\hline How often have you participated in a similar experiment involving trading of stock and options in a market? & Number & 0.064 & 1.064 & 0.051 & 0.538 \\
\hline
\end{tabular}




\subsection{Additional Data on Trading Volume}

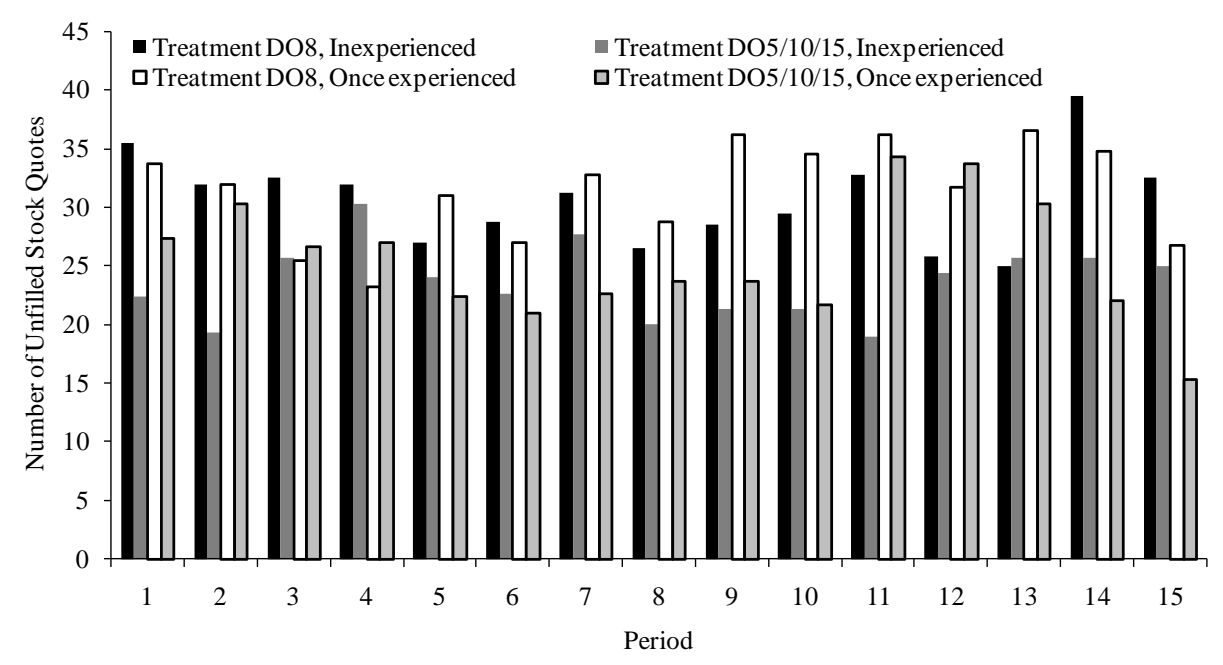

(a)

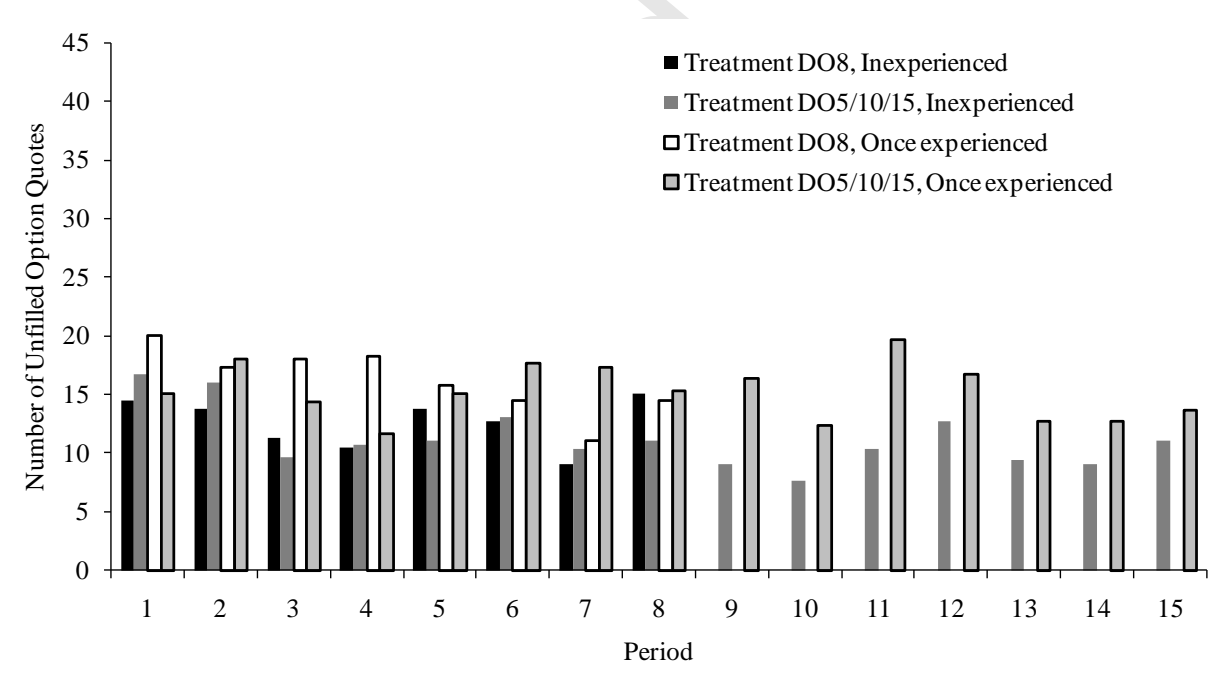

(b)

Figure A.1 Mean number of unfilled quotes. The two graphs show, for each treatment and two levels of experience, the mean over all sessions of the number of quotes that did not lead to transactions in the stock market (c) and option market (d). Inexperienced subjects have never participated in an experiment of this type and once experienced subjects are the same individuals in the second trading session. 
Table A.2

\section{Trading Volume}

This table lists the mean number of transactions and unfilled bids and asks in the stock market, and the mean number of transactions and unfilled offers in the option market, over all sessions.

\begin{tabular}{|c|c|c|c|c|c|c|c|c|c|c|}
\hline \multirow[b]{2}{*}{ Measure } & \multirow[b]{2}{*}{ Round: } & \multicolumn{3}{|c|}{ DO8 } & \multicolumn{3}{|c|}{ DO5/10/15 } & \multicolumn{3}{|c|}{ Both } \\
\hline & & 1 & 2 & All & 1 & 2 & All & 1 & 2 & All \\
\hline \multicolumn{2}{|c|}{ Stock transactions } & 151.8 & 101.3 & 126.5 & 137.0 & 116.0 & 126.5 & 145.4 & 107.6 & 126.5 \\
\hline \multicolumn{2}{|c|}{ Ufilled stock quotes } & 459.0 & 470.8 & 464.9 & 354.3 & 382.0 & 368.2 & 414.1 & 432.7 & 423.4 \\
\hline \multicolumn{2}{|c|}{ Option transactions } & 35.5 & 32.5 & 34.0 & 76.3 & 71.0 & 73.7 & 53.0 & 49.0 & 51.0 \\
\hline \multicolumn{2}{|c|}{ Unfilled option quotes } & 100.5 & 129.3 & 114.9 & 166.0 & 228.0 & 197.0 & 128.6 & 171.6 & 150.1 \\
\hline
\end{tabular}

\subsection{Explanation of Bubble Measure Calculations}

This section explains the origin of the bubble measures reported in Table III. From Ackert and Church (2001), we report the bubble measures found in their Table 3, p. 17, columns 3 (Duration), 4 (Amplitude), and 7 (Turnover). The measures from Porter and Smith (1995) are taken from their Table 5, p. 521. Their Amplitude is reported in columns 2 and 5, Duration in columns 3 and 6, and Turnover in columns 4 and 7. The sample size is taken from Table 4 and the notes of Table 4, p. 519. In addition to the sample size listed for the Porter and Smith (1995) baseline experiments in our Table III, three baseline experiments are mentioned there, but it is not made clear whether they were conducted with inexperienced or experienced subjects. Hence, these three experiments are included in the sample size number of neither the inexperienced nor the experienced measures. Regarding Van Boening et al. (1993), Amplitude is taken from Table 1, p. 181. We calculate the mean of the price amplitude (column 2) for series 1 and series 2 (the two double auction series), divided by 3.75 , which is the intrinsic value of the share in period 1 of their experiment. This serves to transform their amplitude measure into Amplitude, as reported in section II.A. of this article. The same calculation is performed for Turnover (column 4).

\section{ACKNOWLEDGMENTS}

For the original idea of employing digital options in a market of the type introduced in Smith et al. (1988), we thank Hubertus Hofkirchner. Our thanks furthermore goes to Lucy Ackert, James Ang, Nicole Palan, Ron King, Ulrike Leopold-Wildburger, Roland Mestel and Peter Steiner for help and invaluable comments, to Dave Porter for providing detailed data on Porter and Smith (1995), to Dan Gode and Shyam Sunder for providing detailed data on Gode and Sunder (1993), to Alexander Brauneis for organizing two experimental sessions at the University of Klagenfurt, to 
Stefan Schmid and Urs Fischbacher for their help with the z-Tree software, and to our two anonymous referees, whose comments considerably improved this article. We particularly thank Catherine Eckel and Simon Gächter for inspiring and encouraging us to take up experimental research during conversations at their seminar at the European Forum Alpbach 2005 and Simon's presentations at the Graz Schumpeter Lectures 2006.

\section{REFERENCES}

Ackert, L.F., Charupat, N., Church, B.K., Deaves, R., 2006. Margin, short selling, and lotteries in experimental asset markets. Southern Economic Journal 73, 419-436.

Ackert, L.F., Church, B.K., 2001. The effects of subject pool and design experience on rationality in experimental asset markets. Journal of Psychology and Financial Markets 2, 6-28.

Bai, J., Perron, P., 2003. Computation and analysis of multiple structural change models. Journal of Applied Econometrics 18, 1-22.

Bank for International Settlements, 2009. Quarterly review 12/2009.

Bank for International Settlements, 2010. Quarterly review 03/2010.

Caginalp, G., Porter, D., Smith, V. L., 2001. Financial bubbles: Excess cash, momentum, and incomplete information. Journal of Psychology and Financial Markets 2, 8099.

Chakravarty, S., Gulen, H., Mayhew, S., 2004. Informed trading in stock and sption markets. Journal of Finance 59, 1235-1257.

Corgnet, B., Kujal, P., Porter, D., 1983. Uninformative announcements and asset trading behavior. Universidad Carlos III De Madrid Working Paper 07-83.

Cox, C.C., 1976. Futures trading and market information. Journal of Political Economy $84,1215-1237$.

Crowley, S., Sade, O., 2004. Does the option to cancel an order in a double auction market matter? Economic Letters 83, 89-97.

De Jong, C., Koedijk, K.G., Schnitzlein, C.R., 2006. Stock market quality in the presence of a traded option. Journal of Business 79, 2243-2274.

Easley, D., O’Hara, M., Srinivas, P.S., 1998. Option volume and stock prices: Evidence on where informed traders trade. Journal of Finance 53, 431-465.

Figlewski, S., Webb, G., 1993. Options, short sales, and market completeness. Journal of Finance 48, 761-777.

Fischbacher, U., 2007. z-Tree: Zurich toolbox for ready-made economic experiments. Experimental Economics 10, 171-178.

Fisher, E.O'N., Kelly, F.S., 2000. Experimental foreign exchange markets. Pacific Economic Review 5, 365-387.

Forsythe, R., Palfrey, T.R., Plott, C.R., 1982. Asset valuation in an experimental market. Econometrica 50, 537-567.

Forsythe, R., Palfrey, T.R., Plott, C.R., 1984. Futures markets and informational efficiency: A laboratory examination. Journal of Finance 39, 955-981. 
Friedman, D., Harrison, G.W., Salmon, J.W., 1983. The informational role of futures markets: Some experimental evidence. In: Streit, M.E. (Ed.), 1983. Futures markets - modelling, managing and monitoring futures trading. Oxford: Basil Blackwell, 124-164.

Friedman, D., Harrison, G.W., Salmon, J.W., 1984. The informational efficiency of experimental asset markets. Journal of Political Economy 92, 349-408.

Gan, J., 2007. The real effects of asset market bubbles: Loan- and firm-level evidence of a lending channel. Review of Financial Studies 20, 1941-1973.

Gode, D.K., Sunder, S., 1993. Allocative efficiency of markets with zero-intelligence traders: Market as a partial substitute for individual rationality. Journal of Political Economy 101, 119-137.

Haruvy, E., Lahav, Y., Noussair, C.N., 2007. Traders' expectations in asset markets: Experimental evidence. American Economic Review 97, 1901-1920.

Haruvy, E., Noussair, C.N., 2006. The effect of short selling on bubbles and crashes in experimental spot asset markets. Journal of Finance 61, 1119-1157.

Hasbrouck, J., 1995. One security, many markets: Determining the contributions to price discovery. Journal of Finance 50, 1175-1199.

Hirota, S., Sunder, S., 2007. Price bubbles sans dividend anchors: Evidence from laboratory stock markets. Journal of Economic Dynamics \& Control 31, 1875-1909.

Hussam, R.N., Porter, D., Smith, V.L., 2008. Thar she blows: Can bubbles be rekindled with experienced subjects? American Economic Review 98, 924-937.

James, D., Isaac, R.M., 2000. Asset markets: How they are affected by tournament incentives for individuals. American Economic Review 90, 995-1004.

Jayaraman, N., Frye, M.B., Sabherwal, S., 2001. Informed trading around merger announcements: An empirical test using transaction volume and open interest in options markets. Financial Review 37, 45-74.

King, R.R., 1991. Private information acquisition in experimental markets prone to bubble and crash. Journal of Financial Research 14, 197-206.

King, R.R., Smith, V.L., Williams, A.W., Van Boening, M., 1993. The robustness of bubbles and crashes in experimental stock markets. In: Day, R., Chen, P., 1993. Nonlinear dynamics and evolutionary economics. Oxford: Oxford University Press, 183-200.

Lei, V., Noussair, C.N., Plott, R., 2001. Nonspeculative bubbles in experimental asset markets: Lack of common knowledge of rationality vs. actual irrationality. Econometrica 69, 831-859.

Luckner, S., Weinhardt, C., 2007. How to pay traders in information markets: Results from a field experiment. Journal of Prediction Markets 1, 147-156.

Noussair, C.N., Powell, O., 2008. Peaks and valleys: Experimental asset markets with non-monotonic fundamentals. CentER Discussion Paper 2008-49, Tilburg University.

Noussair, C.N., Robin, S., Ruffieux, B., 2001. Price bubbles in laboratory asset markets with constant fundamental values. Experimental Economics 4, 87-105.

Noussair, C.N., Tucker, S., 2006. Futures markets and bubble formation in experimental asset markets. Pacific Economic Review 11, 167-184.

O’Hara, M., 1995. Market microstructure theory. Cambridge, MA: Blackwell.

Oechssler, J., Schmidt, C., Schnedler, W., 2007. Asset bubbles without dividends - An experiment. SonderForschungsBereich 504 Working Paper 07-01, University of Mannheim. 
Oliver, P., 2007. Financial binary betting, styles, valuations and deductions from data. Journal of Prediction Markets 1, 127-146.

Porter, D.P., Smith, V.L., 1995. Futures contracting and dividend uncertainty in experimental asset markets. Journal of Business 68, 509-541.

Ross, S.A., 1976. Options and efficiency. Quarterly Journal of Economics 90, 75-86.

Smith, V.L., 1962. An experimental study of competitive market behavior. Journal of Political Economy 70, 111-137.

Smith, V.L., Suchanek, G.L., Williams, A.W., 1988. Bubbles, crashes and endogenous expectations in experimental spot asset markets. Econometrica 56, 1119-1151.

Smith, V.L., van Boening, M.V., Wellford, C.P., 2000. Dividend timing and behavior in laboratory asset markets. Economic Theory 16, 567-583.

Sunder, S., 1995. Experimental asset markets: A survey. In: Kagel, J.H., Roth, A.E. (Eds.). Handbook of experimental economics, Princeton: Princeton University Press, 445-500.

Van Boening, M.V., Williams, A.W., LaMaster, S., 1993. Price bubbles and crashes in experimental call markets. Economic Letters 41, 179-185.

\section{ROLE OF THE FUNDING SOURCE}

Funding was provided by the Faculty of Social and Economic Sciences at the KarlFranzens-University of Graz. The funding source did not have any role in study design; in the collection, analysis, and interpretation of data; in the writing of the report; and in the decision to submit the paper for publication. 